DOI 10.1515/linpo-2016-0010

\title{
Finding the best fit for direct and indirect causation: a typological study
}

\author{
Natalia Levshina \\ Leipzig University (ERC Project "Grammatical Universals") \\ e-mail: natalevs@gmail.com
}

\begin{abstract}
Natalia Levshina. Finding the best fit for direct and indirect causation: a typological study. The Poznań Society for the Advancement of Arts and Sciences, PL ISSN 0079-4740, pp. 65-82

The contrast between direct and indirect causation is the most widely discussed semantic distinction in the literature on causative constructions. This distinction has been claimed to correlate with a number of formal parameters, such as formal distance, productivity and length, which are linked to different functional and diachronic explanations based on the principles of iconicity and economy. The present study tests these claims on a typologically representative sample of languages from 46 diverse families, examining four formal variables and their association with (in)directness of causation. According to the data, formal length displays the most pervasive association with the semantic distinction in question, which supports the economy-based explanation. In addition, the relative prominence of the other formal parameters depends on the type of causatives and their stage of grammaticalization.
\end{abstract}

Keywords: causatives, iconicity, economy, productivity, autonomy, distance, formal length

\section{Causative constructions: meaning, form and their correlation}

Causative constructions express causative situations, which involve at least two participants, which are traditionally called the Causer and the Causee. A causative situation consists of two events, or microsituations, which are called the causing and caused events. An example is provided in (1). The causing event involves the Causer (i.e. Mary) acting in some way upon the Causee (i.e. Jack), and the caused event is represented by the Causee undergoing a change or performing an action. The caused event is usually specific (i.e. Jack signs the contract), while the causing event is often unspecified (i.e. Mary did something that affected Jack).

(1) Mary made Jack sign the contract. 
Causative situations vary with regard to different semantic parameters. Consider the examples in (2), where (2a) expresses direct causation with tight spatiotemporal integration of the causing and caused events, while (2b) conveys indirect causation, which is characterized by a lack of spatiotemporal overlap between the causing and caused events and direct contact between the Causer and the Causee.

(2) a. John killed Bill in his mansion last Friday...

?? ... by shooting him in the forest on Wednesday.

? $\quad$... by tampering with his gun.

? ... by not preventing his suicide.

b. John caused Bill to die in his mansion last Friday...

... by shooting him in the forest on Wednesday.

... by tampering with his gun.

... by not preventing his suicide.

Other semantic distinctions often mentioned in the literature include factitive vs. permissive causation, as in (3a), intentionally or non-intentionally acting Causer, as in (3b), non-involved or involved Causer, as in (3c) and natural or forceful causation, as in (3d).

(3) a. I made him run. - I let him run.

b. I made him run by promising him 100 dollars. - I chased him off inadvertently.

c. I had him come to my friends, but stayed at home myself. - I brought him to my friends (and came, too).

d. I had him run. - I forced him to run.

Languages have many ways of expressing causation, which vary according to the representation of the causing and caused events. Consider examples in (4).

(4) a. John killed Bill.

b. Turkish öl- 'die' > öl-dür- 'kill'

c. John caused Bill to die.

The verb kill in (4a) is an example of a lexical causative, where the causing and caused events are merged in one word. The Turkish verb is a morphological causative, which is formed by a causative morpheme attached to the morpheme or stem representing the caused event. The sentence in (4c) exemplifies a syntactic causative (other commonly used terms are analytic and periphrastic), where the causing and caused events are expressed by different predicates.

However, there exist a number of constructions that do not fit these discrete types perfectly. It is more correct, therefore, to speak about the causative continuum (e.g. Comrie 1981: Chapter 8; Shibatani \& Pardeshi 2002). A typical in-between example is the causative construction with faire in French, as in j'ai fait courir Paul 'I have made Paul run', which behaves very differently from most other two-predicate constructions in the language, such as j'ai demandé à Paul de courir 'I have asked Paul to run'. In the faire-construction, there can be hardly any elements inserted between the first and the second verb, except for the tense and person markers, and the subject of the infinitive is 
expressed after the infinitive, similar to the object of a simple predicate. As a consequence, faire courir can be viewed as a single complex predicate (Comrie 1981: 162), where the predicates are more integrated than those in a typical syntactic causative. ${ }^{1}$ Another problematic example is let go (of), as in John let go of Bill's hand. This lexicalized expression retains the form of a syntactic causative let + VINF, but the two verbs follow one another, unlike in the other constructions with let, e.g. John let Bill go.

Many linguists observe a correlation between the formal and semantic parameters of causatives. The semantic parameter that has enjoyed the greatest attention in the literature is (in)directness of causation. For instance, Haiman (1985) provides many examples to demonstrate that formal distance between units correlates with the conceptual distance between the events they represent, including the causing and caused events in causative constructions. His scale of linguistic distance (Haiman 1985: 105) is shown in (5).

(5) a. X \# A \# B \# Y

b. $\mathrm{X} \# \mathrm{~A} \# \mathrm{Y}$

c. $\mathrm{X}+\mathrm{A} \# \mathrm{Y}$

d. $X \# Y$

e. $\mathrm{X}+\mathrm{Y}$

f. $\mathrm{Z}$

In this cline, $\mathrm{X}$ and $\mathrm{Y}$ are the linguistic expressions of interest, $\mathrm{A}$ and $\mathrm{B}$ are other intervening units, \# represents a word boundary, + stands for a morpheme boundary, and $\mathrm{Z}$ is a morpheme where $\mathrm{X}$ and $\mathrm{Y}$ are fused. It is important to note that Haiman's cline in (5) involves not only formal distance per se, but also autonomy of $\mathrm{X}$ and $\mathrm{Y}$. For example, the types (5a) X \# A \# B \# Y and (5b) X \# A \# Y differ only in distance between $\mathrm{X}$ and $\mathrm{Y}$, whereas (5d) X \# Y and (5e) X + Y differ only in autonomy, representing two words or two morphemes, correspondingly. As for the types (5e) $\mathrm{X}+\mathrm{Y}$ and (5f) Z, they differ both in distance and autonomy. The formal distance between the forms $\mathrm{X}$ and $\mathrm{Y}$ and/or their autonomy decrease from (5a) to (5e), until they are fully fused in (5f).

Haiman argues that this formal scale correlates with conceptual integration, which can be interpreted as more and less direct causation. Consider the sentences from Haiman (1983: 784) in (6), where (6a) contains syntactic causatives caused + to fall/die/rise and represents a large distance between $\mathrm{X}$ and $\mathrm{Y}$, which can be formalized as $\mathrm{X}$ \# A \# B \# $\mathrm{C}$ \# Y, whereas (6b) contains lexical causatives felled/killed/raised and illustrates $\mathrm{Z}$, the most cohesive type:

(6) a. I caused the tree to fall/the chicken to die/the cup to rise to my lips.

b. I felled the tree/killed the chicken/raised the cup to my lips.

According to Haiman, the syntactic causatives in (6a) suggest an absence of direct physical contact between the Causer and the Causee and therefore the connotation that

${ }^{1}$ Some authors (cf. Kulikov [2001: 886-887] with further references) regard only the monoclausal constructions like faire $+\mathrm{V}$ as the only truly syntactic causatives. In the present paper, syntactic causatives are an umbrella term for a number of different causatives, which are represented by different autonomous words, including monoclausal and biclausal causatives, light verb constructions and serial verb constructions. 
the Causer has magical powers, whereas the corresponding lexical causatives in (6b) do not have such connotations. Haiman presents this correlation as an example of iconic motivation in language, where iconicity means a correspondence between linguistic form and meaning. However, it is not clear whether we deal with iconicity of conceptual and formal distance between event $\mathrm{X}$ and event $\mathrm{Y}$, or with iconicity of conceptual and formal dependence between event $\mathrm{X}$ and event $\mathrm{Y}$. Although it may be difficult to distinguish between conceptual distance and autonomy, it is easy to find examples when formal distance and autonomy do not overlap. Compare, for example, the English indirect periphrastic causatives have smb. do smth. and get smb. to do smth. In both causatives, the degree of autonomy of the causative auxiliary and the effected predicate is identical, following Haiman's approach. However, the have-causative displays a smaller formal distance between the predicates than the get-causative because the latter contains the particle to.

A different claim is made by Shibatani \& Pardeshi (2002: Section 5), who argue that the semantic distinction between direct and indirect causation closely corresponds to the degree of productivity of constructions. Moreover, (in)directness correlates with productivity stronger than with such well-established formal classes as lexical, morphological and syntactic causatives:

Cross-linguistically, productive forms align (whether they are morphological or periphrastic) in expressing indirect causation, and lexically restricted forms align (whether they are morphologically unanalyzable or morphologically complex) in expressing direct causation. (Ibid.: 112)

One piece of evidence comes from Japanese morphological causatives. Consider the verb oros- 'bring down' from ori- 'come down', which represents a non-productive construction, in contrast with ori-sase- 'cause to come down', which is formed with a productive suffix -(s)ase. The non-productive form expresses direct causation, similar to lexical causatives, whereas the productive form conveys indirect causation (Comrie 1981: 163).

As another illustration, one can take the causative prefixes $a$ - and as- in Amharic (Amberber 2000). The former only applies to intransitive unaccusative verbs (e.g. verbs of state, change of state and motion, e.g. 'exist', 'melt', 'grow', 'enter') and transitive verbs of ingestion (e.g. 'eat' and 'drink'), but not to unergative verbs (e.g. 'dance' or 'laugh'). It expresses situations when the Causer is physically involved in the causation (Ibid.: 317-320), as in (7b). The causative prefix as- applies to both transitive and intransitive verbs of all classes and expresses causation types when the Causer is not directly involved in the caused event, as in (7c). Again, the (in)directness distinction is aligned with productivity. Since both causatives are morphological, the traditional three-way classification does not correlate with this semantic distinction.

(7) Amharic

a. aster wat't'a-čč

A. exit+PERF-3F

'Aster exited.'

b. lamma aster-in a-wat't'a-t 


\author{
L. A.-ACC CAUS-exit+PERF+3M-3FO \\ 'Lemma took Aster out (as in 'out of the house').' \\ c. lamma aster-in as-wat't'a-t \\ L. A.- ACC CAUS-exit+PERF+3M-3Fo \\ 'Lemma made/let Aster exit.' (Amberber 2000: 320)
}

These and other examples (cf. Shibatani \& Pardeshi 2002: Section 5) demonstrate that more productive morphological causatives often express indirect causation, similar to syntactic causatives, and less productive ones express direct causation, similar to lexical causatives. However, they belong to the same traditional class of morphological causatives. The degree of grammatical autonomy and the formal distance between the root and the affix also remain the same, as follows from the examples. Thus, productivity may be more directly aligned with the (in)directness distinction than autonomy and formal distance. According to Shibatani \& Pardeshi, this alignment is a result of grammatical change. However, iconicity plays a role, as well, in that the strength of connection between the non-causal root and the causativizing element correlates with the strength of the conceptual integration of the causing and caused events.

Another parameter that seems to be correlated with the (in)directness distinction is the formal length of causative markers. To the best of my knowledge, this idea has been first formulated in a straightforward way by Haspelmath (2008), ${ }^{2}$ who argues that the form-meaning mapping, which have been found in causatives by Haiman and other proponents of iconic motivation, can be interpreted in terms of economy. Direct causation is expressed by shorter forms because it is more frequent than indirect causation, which is usually expressed by longer forms. For instance, kill is both shorter and more frequent than cause to die. This efficient form-meaning mapping is based on the Principle of Least Effort (Zipf 1949) and the principle of economy (Haiman 1983). Shorter units are usually less autonomous than longer ones and tend to be attached to their hosts, which explains why linguists like Haiman also observe the differences in autonomy and distance. In a similar vein, Haspelmath (2016) (in this issue) argues that the frequency of occurrence of verbs in causal and non-causal contexts determines the verbs' preference for causative or anti-causative derivations. At the same time, the verbs' semantic properties (most importantly, their rank on the spontaneity scale) do not play a direct role in determining the direction of derivation.

For the sake of completeness, one should also mention Dixon's (2000) notion of compactness, which correlates with numerous semantic distinctions in different languages, including the directly and indirectly acting Causer. Dixon charts a cline from the most compact lexical causatives via morphological causatives and complex predicates (e.g. the above-mentioned faire + VINF in French) to the least compact periphrastic causatives.

\footnotetext{
${ }^{2}$ Already Nedyalkov \& Silnitsky (1973: 8) argued that the causative markers that derive causatives from transitive base verbs are more complex than those that derive causatives from intransitive base verbs. Since the causatives derived from transitives usually express distant causation, while the ones derived from intransitives convey compact causation (Ibid.: 14), and the complexity of causative markers is correlated with their length, one can make a logical conclusion that there is also a positive correlation between the semantic distance and length of causative markers. I thank the anonymous reviewer for drawing my attention to this fact.
} 
Although he does not mention this explicitly, this cline can be seen as a combination of autonomy and distance. However, he also says that length may be responsible for finer-grained distinctions within these major types. For instance, shorter causative affixes produce more compact morphological causatives than longer ones do (Dixon 2000: 75). Therefore, one would expect autonomy, distance and length to correlate with (in)directness and other semantic distinctions.

Thus, the previous research suggests that direct and indirect causation can be correlated with formal distance, autonomy, productivity and length. However, to the best of my knowledge, these hypotheses have not been tested and compared systematically on typologically diverse data. The aim of the present study is to fill this gap and to investigate whether these formal parameters correlate with (in)directness of causation in different languages, and to what extent. To answer these questions, I will use a sample of languages from 46 different language families. The formal and semantic information used in the study comes from various reference grammars and research papers.

The rest of the paper is organized as follows. First, I describe the typological data and variables in Section 2. Next, Section 3 presents the answers to the research questions based on quantitative analyses of the typological data. Finally, a discussion of the results is offered in Section 4.

\section{Typological data and variables}

\subsection{Language sample}

For the purposes of this study, I selected 46 languages, where (in)directness or similar semantic distinctions were mentioned as a distinctive semantic parameter of two or more different causative constructions. Each language represents one language family, based on the genetic classification from the World Atlas of Language Structures online (Dryer \& Haspelmath 2013). The list of languages is available in the Appendix. ${ }^{3}$ The languages represent six major geographical and linguistic areas (Africa, Australia, Eurasia, North America, Papua/Austronesia and South America). The geographical distribution of the languages is shown in Figure 1. The map was produced with the help of the add-on packages ggplot 2 and ggmap in $\mathrm{R}$ (R Core Team 2016). The semantic and formal properties of the causative constructions were taken from reference grammars and research articles. These differences are described in Sections 2.2 and 2.3.

\subsection{Semantic distinctions}

The data points in my data set were contrasting pairs of causative constructions, rather than individual constructions. If the data are available for two causative constructions in a language, then the language has one contrast between $\mathrm{Cx} 1$ and $\mathrm{Cx} 2$. If three

\footnotetext{
${ }^{3}$ The full data are available at https://github.com/levshina/TypoCaus.
} 


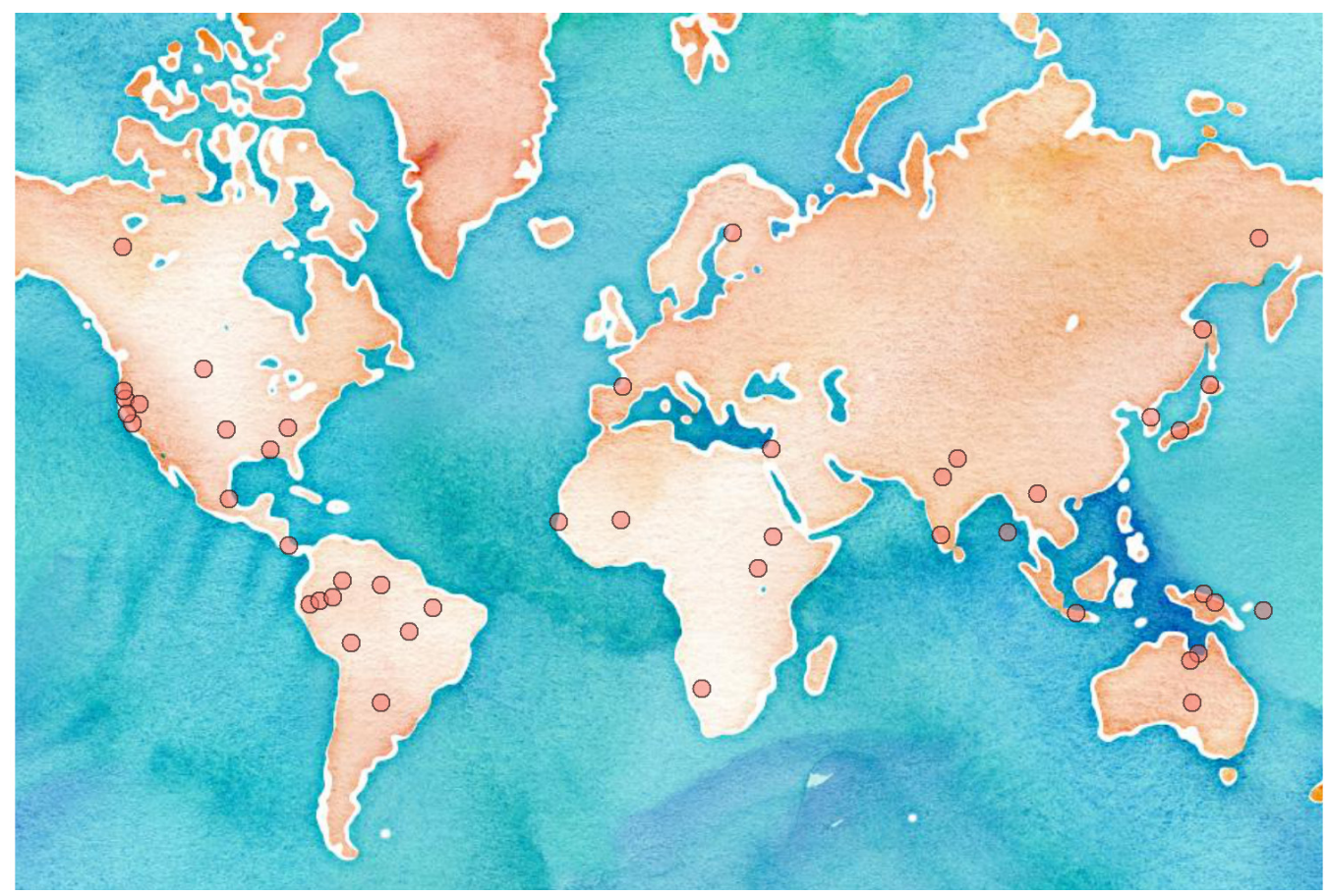

Figure 1. Geographical distribution of the languages in the sample

constructions are described, there are three possible contrasts between $\mathrm{Cx} 1$ and $\mathrm{Cx} 2, \mathrm{Cx} 2$ and $\mathrm{Cx} 3$ and $\mathrm{Cx} 1$ and $\mathrm{Cx} 3$. For four constructions, six contrasts are possible, and so on.

From all possible semantic distinctions between the constructions in a language, I selected only those that can be interpreted as direct vs. indirect causation and the degree of integration of the causing and caused events or closely related functions. The full list of the distinctions used in the grammars and papers, which I interpreted as direct vs. indirect, is as follows:

- direct vs. indirect causation;

- strong vs. weak integration of the causing and caused events, separability of events;

- manipulative vs. directive causation;

- contact vs. distant causation;

- direct vs. mediated causation;

- the Causee as non-controlling undergoer vs. controlling agent (and therefore the main source of energy);

- default vs. ballistic causation;

- factitive vs. permissive causation;

- caused state (or change of state) vs. caused activity;

- default causation vs. causation with human intermediary;

- default vs. curative or 'indefinite' causation;

- general vs. 'mild' or 'weak' causation;

- default vs. caused by ordering X to do Y; 
- implicative vs. non-implicative causal relationships.

As an illustration, consider two causative constructions in the Amur dialect of Nivkh (a Paleosiberian isolate) in (8). One of the constructions consists of a non-productive causative suffix $-u$ and expresses contact factitive causation, as in (8b), while the other contains a productive suffix $-k u /-\gamma u /-g u /-x u$ and usually expresses distant factitive or permissive causation (Nedjalkov \& Otaina 2013: 133), as in (8c).

(8) Nivkh (isolate), the Amur dialect
a. Lep t'e-d.
bread be.dry-IND
'The bread dried up.'
b. If lep + se-u-d.
$\mathrm{s} /$ he bread+be.dry-CAUs-IND
'He dried up the bread' (for dried crusts).

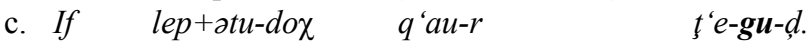
s/he bread+cover-suP not.be-CONv:NAR:3sg be.dry-CAUS-IND
'Not covering the bread, he let (it) dry up.' (Nedjalkov \& Otaina 2013: 234)

A less common semantic contrast is found in Ainu, as shown in (9), where (9b) is an example of the causative construction which expresses 'normal' causation, whereas (9c) is an illustration of so-called indefinite causation, when the Causee is not known or is omitted due to politeness reasons. The latter type can be perceived as less direct because the Causee is not affected (cf. Kemmer \& Verhagen 1994). This type is also known as curative causation. Similar constructions exist in English, namely, have/get smth. done (by smb.), e.g. I've had my hair cut.

(9) Ainu (isolate)
a. $e$ 'to eat'
b. é-re 'to have (someone) eat, feed'
c. e-yar 'to have something eaten' (Tamura 2000: 214)

Often, a contrast involves more than two fine-grained distinctions. This is not surprising, since the semantic parameters of causatives are often strongly correlated (Levshina 2016). Example (10) from a Cariban language Waimiri-Atroarí illustrates a combination of the factitive/permissive distinction and implicativity. The causative suffix $-p y$ in (10a) expresses factitive causation, whereas the periphrastic construction with injaky 'let/permit' and particle tre'me shown in (10b) expresses permission. In addition, causation in (10b) is non-implicative, which means that the causative does not express whether the caused event actually happens or not. This serves as an indication of weaker event integration (Givón 1980).

(10) Waimiri-Atroarí (Cariban)
a. Ka k-yeepitxah-py-pia.
3рro 1+2o-laugh-CAUS-IMMP
'She/he made us laugh.' (Bruno 2003: 100)
b. Aa ka m-injaky-piany wyty ipy-na tre'me.
1 PRO ? 2o-permit/let-RECP meat look for-? PART


'I permitted you to/let you leave to hunt.' (Bruno 2003: 103) ${ }^{4}$

In many cases, the authors do not specify the nature of causation, or call it 'general' or 'default', treating the corresponding construction as a purely grammatical tool for increasing valency. For example, one can find such distinctions as default vs. permissive, or default vs. curative causation. In this study, I assume that the default construction is non-permissive or non-ballistic, correspondingly, following the Principle of No Synonymy (Goldberg 1995: 67): "If two constructions are syntactically distinct, they must be semantically or pragmatically distinct." Even if two constructions are interchangeable to some extent, the speaker will be less likely to use the 'default' construction if there is a more specific alternative that expresses the intended meaning. The labels 'general' or 'default' may be motivated by the fact that the corresponding construction is more frequent.

In total, I found 74 contrasts related to (in)directness in 46 languages. Other semantic distinctions, which are not considered in the present study, involve forceful, unintentional, distributive, iterative causation and other types. They are excluded because they cannot be very easily interpreted in terms of direct and indirect causation. Moreover, doing so would mean that these notions would become so inflated that they lose their informativity.

\subsection{Formal parameters}

All constructional pairs that have the semantic distinctions listed in 2.2 were coded for the four formal parameters mentioned in Section 1: distance, autonomy, productivity and length. The coding was relative, rather than absolute. This means, for example, that I did not code the length of constructions $\mathrm{X}$ and $\mathrm{Y}$ separately, but only coded whether $\mathrm{X}$ was shorter than $\mathrm{Y}$, longer than $\mathrm{Y}$ or equally long as $\mathrm{Y}$. As X I chose the construction that expressed (more) direct causation or one of its modifications from the list in Section 2.2. The other construction, which expressed (more) indirect causation, was treated as Y.

The contrasts between $\mathrm{X}$ and $\mathrm{Y}$ were coded for the four formal variables using the guidelines described below.

1. Relative distance. This variable reflects the differences in the linguistic distance between the elements representing the causing and caused events in $\mathrm{X}$ and $\mathrm{Y}$. The formal criterion is the number of phonological segments (i.e. phones or phonemes) in the in-between elements, including affixes and clitics and autonomous words, which are obligatorily used between the elements representing the cause and effect. According to the iconicity-based account, we can expect the elements in $\mathrm{X}$ to be less distant than those in $\mathrm{Y}$ (i.e. $\mathrm{X}<\mathrm{Y}$ ).

2. Relative autonomy, which reflects the differences in the degree of autonomy of the elements representing the causing and caused events in $\mathrm{X}$ and $\mathrm{Y}$. It is similar to bondedness, "the degree to which a sign depends on, or attaches to, other sign" (Lehmann 1995: 123). To determine the level of autonomy, I used the following cline:

\footnotetext{
${ }^{4}$ The author of the cited grammar used question marks to gloss some units, as in this example.
} 
(11) one morpheme $<$ morphemes in a word $<$ clitic + host $<$ parts of one verbal phrase (monoclausal) $<$ clauses in a sentence (biclausal) ${ }^{5}$

The minimal autonomy is observed in lexical causatives, such as kill, break or raise. The causing and caused events are merged in one word or morpheme. In morphological causatives, the non-causal verb and causative morpheme are more autonomous. In syntactic causatives, such as cause $X$ to die, the degree of autonomy is even higher because the words or clauses expressing the causing and caused events are more autonomous units. Again, the iconicity-based account predicts that $\mathrm{X}$ will tend to be less autonomous than $\mathrm{Y}$ (i.e. $\mathrm{X}<\mathrm{Y}$ ).

3. Relative productivity, which represents the differences in productivity between $\mathrm{X}$ and Y. Productivity is the ability of a unit or pattern to freely combine with other units. For example, lexical causatives display zero productivity, whereas periphrastic expressions like John caused Bill/Jane/Mary to run/die/go... display high productivity. Some morphological causative patterns can be more productive than others, as the examples from Amharic and Japanese in Section 1 demonstrate. A common instance of productivity asymmetries is when some causatives can be formed with all verbs, and some only with intransitives (cf. Dixon 2000). Following Shibatani \& Pardeshi (2002), one can expect $\mathrm{X}$ to be less productive than $\mathrm{Y}$ (i.e. $\mathrm{X}<\mathrm{Y}$ ).

4. Relative length, which tells about the difference in the length of X compared to Y. Many different operationalizations of length are possible, including very sophisticated ones (cf. Bybee et al. 1994: Ch. 4, who consider vowels to be longer than consonants, also distinguishing between long and short consonants and vowels). When available, relative length was based on the number of segments in grammatically equivalent forms of the same verb. For example, Filomeno (Totonacan) has construction $\mathrm{X}$ with the prefix maa-, e.g. maa-xiksw-i 'I asphyxiate you' (directly), and construction Y with the prefix maqa-, e.g. maqa-xikswá 'I make you asphyxiate' (indirectly, e.g. by making you laugh while you eat) (McFarland 2009: 155). In this situation, one can directly compare the number of segments in the words. When such immediate contrasts were not available, I compared the number of segments in the causative morphemes or auxiliaries and other obligatory elements, such as complementizers or finite markers on the auxiliary in the examples. This simple approach, however, leads to the same results as when I took into account the difference between vowels and consonants and their length, following the more sophisticated method employed by Bybee et al. (1994). The reason is that the differences in length are rather conspicuous. When there were different allomorphs, I took the average length. Following Haspelmath's (2008) predictions based on the principle of economy, we can expect direct causation forms $\mathrm{X}$ to be shorter than indirect causation forms $\mathrm{Y}$ (i.e. $\mathrm{X}<\mathrm{Y}$ ).

To illustrate the coding procedure, let us compare two morphological causatives from Urarina (language isolate). One of them typically expresses direct causation and is formed with the help of the suffix $-a$ (cf. 12a). The other usually expresses indirect causation

${ }^{5} \mathrm{I}$ 'm aware of the fact that the categories in (11) are problematic as comparative concepts for language comparison. However, the comparisons made in this study were only done within one specific language. I relied on the language-specific categories used by the authors of the grammars in the hope that those categories represent the differences in the degree of autonomy adequately. 
and contains the suffix -erate (cf. 12b). The first causative is shorter and less productive than the second, being attached only to intransitives (Olawsky 2006: 609-621). The causatives, however, do not seem to differ in terms of distance from the non-causal root and autonomy. ${ }^{6}$

(12) Urarina (isolate)

a. eno- $a$ 'enter' > eno-a- $a$ 'make enter'

naltt- $a$ 'fall' > naltt-a-a 'drop' (Olawsky 2006: 616)

b. satt-a 'cut' > sa-eratia 'make cut'

hjani-a 'leave' > hjane-ratia 'make leave' (Olawsky 2006: 610-611)

\section{Quantitative analyses: which parameter makes the best match with (in) directness?}

\subsection{Correlations between formal parameters and (in)directness}

This section presents the quantitative analyses based on the data described in Section 2. Table 1 displays the counts for the individual contrasts (74 in total) where the formal parameters behave in accordance with the predictions $(\mathrm{X}<\mathrm{Y})$, against them $(\mathrm{X}>\mathrm{Y})$, or display no association with (in)directness $(\mathrm{X}=\mathrm{Y})$. Table 2 shows the number of languages. The counts are lower because some languages have more than one contrasting pair. As an example, compare the bottom rows in the column " $\mathrm{X}<\mathrm{Y}$ ". The number 59 (Table 1) means that 59 contrasts were found where $\mathrm{X}<\mathrm{Y}$ with respect to length. The number 39 (Table 2) means that these 59 contrasts occurred in 39 languages. Note that the numbers in each row of Table 2 do not add up to the total number of languages (46) because some languages have contrasting pairs that behave differently.

Table 1: Formal parameters associated with (in)directness of causation: number of contrasting pairs

\begin{tabular}{lccc}
\hline \multicolumn{1}{c}{ Parameter } & $\mathrm{X}<\mathrm{Y}$ & $\mathrm{X}=\mathrm{Y}$ & $\mathrm{X}>\mathrm{Y}$ \\
\hline Distance & 44 & 30 & 0 \\
Autonomy & 41 & 33 & 0 \\
Productivity & 40 & 33 & 1 \\
Length & 59 & 13 & 2 \\
\hline
\end{tabular}

Table 2: Formal parameters associated with (in)directness of causation: number of languages

\begin{tabular}{|c|c|c|c|c|}
\hline & Parameter & $\mathrm{X}<\mathrm{Y}$ & $X=Y$ & $X>Y$ \\
\hline
\end{tabular}

${ }^{6}$ With the exception of double causatives, when the suffix -erate follows - $a$, e.g.eno-a-erati-a 'have (someone) enter' (Olawsky 2006: 619). However, double causatives were excluded from this study. 


\begin{tabular}{llll}
\hline Distance & 27 & 26 & 0 \\
Autonomy & 24 & 28 & 0 \\
Productivity & 24 & 28 & 1 \\
Length & 39 & 10 & 2 \\
\hline
\end{tabular}

Both tables reveal that the formal parameter most commonly associated with (in)directness is formal length. $\mathrm{X}$ is shorter than $\mathrm{Y}$ in 39 languages and in 59 contrasts. $\mathrm{X}$ is as long as $\mathrm{Y}$ in only 10 languages and 13 contrasts. There are two exceptions, when $\mathrm{X}$ is longer than $\mathrm{Y}$, which are discussed below. Length is followed by distance: $\mathrm{X}$ is less distant than $Y$ in 27 languages and 44 contrasts, whereas in 26 languages and 30 contrasts there is no difference. Next follows autonomy, with 24 languages and 41 contrasts, where the predictions are met. The parameter the least strongly associated with (in)directness is productivity (24 languages and 40 contrasts, plus one exception from the predicted direction of association).

One of the exceptions related to length is found in Kayardild, where the causative suffix expressing direct causation is actually longer than the one expressing indirect causation, as shown in (13). However, the indirect causative suffix \{-lu-tha\} is also used in the factitive function, which means 'cause to be in a state' (Evans 1995: 355). This functional overlap makes it difficult to say which of the constructions in general is more direct and which is less direct, since causing a state is usually associated with less agentive Causees.

(13) Kayardild (Tangkic)

a. direct causation: suffix -THarrma-tha

thulatha 'descend' > thulatharrmatha 'take down'

dalija 'come' > dalijarrmatha 'bring'

b. indirect causation: suffix \{-lu-tha\}

dulbatha 'sink (intr)' > dulbalutha 'cause to sink, drown' (e.g. by shooting and not allowing to get out of water) (Evans 1995: 355)

Another length-related exception is found in Mutsun (Penutian), where the mediopassive-causative suffix -mpi (causing a change of state) is actually longer than the active causative -si (making someone do something). An example is provided in (14), where (14a) illustrates the causative with -mpi and (14b) the causative with $-s i$.

(14) Mutsun (Penutian)

a. mala- $n$ 'to get wet' > mala-mpi- 'to cause (someone) to get wet' (Okrand 1977: 216)

b. ka.n-was lolle-si-Ø sinnise

I-him babble-CAUS-NPST baby.OBJ

'I made the baby babble.' (Okrand 1977: 219)

This exception can be explained historically: the suffix -mpi in fact represents a fusion of the mediopassive suffix $-n$ and the suffix $-p i$, which no longer occurs autonomously (Okrand 1977: 215-216). 
The third exception, which is related to productivity, is found in Filomeno (Totonacan), where the construction expressing indirect causation maq(a)-, which can only be combined with verbs of emotion and physical sensation, e.g. 'make cry by scolding', is less productive than the prefix maa- expressing direct causation, which is extremely productive (with the exception of postural verbs) (McFarland 2009: Section 5.4.1). Examples of these constructions were provided in Section 2.2. However, one can explain this exception by the fact that the (in)directness contrast is only present in the verbs of emotion and physical sensation. For all other verbs, the default prefix maa- seems to express causative situations that can be interpreted as direct and indirect. Consider an example:

\section{Filomeno (Totonacan)}

kinkaatiimaamaqtaqátni

kin-kaa-tii-maa-maqtaqal-nii-loi

10-O.PL-pass-CAUS-care.for-DAT-PERF

'He made us pass by to care for him.' (McFarland 2009: 153)

Moreover, in two languages, Finnish (Uralic) and Lahu (Sino-Tibetan), there were contrasts without any formal differences. For example, Lahu contains an analytic causative with benefactive auxiliary $p \hat{\imath}$ 'give', e.g. $\check{s} \grave{i}$ 'die' $>\check{s} \grave{i} p \hat{\imath}$ 'make (him) die', which expresses less direct causation (or accidental causation) than the default analytic causative with $c \dot{t}$ 'make, let; originally send on errand', e.g. ši ci 'make him die' (Matisoff 1976: 430). However, I did not manage to detect any differences between the constructions with regard to the formal parameters in the literature. ${ }^{7}$

One might wonder whether these biases towards the predicted differences between $\mathrm{X}$ and $\mathrm{Y}$ (or at least, against the negative differences) are statistically significant. To answer this question, I performed the binomial exact test, using the frequencies of individual contrasts presented in Table 3. The null hypothesis is that there is no difference with regard to the direction of the asymmetry. In other words, we can have either $\mathrm{X}>$ $\mathrm{Y}$ or $\mathrm{X}<\mathrm{Y}$. There is no preference. The alternative hypothesis is that there is a cross-linguistic bias towards $\mathrm{X}<\mathrm{Y}$. The $p$-values of the one-tailed binomial exact test (with the Holm correction for multiple comparisons) are all below $10^{-10}$, which is a very small number. Unfortunately, due to the non-independence of contrasts (many represent one and the same language), these results may be unreliable. To solve this problem, I performed a randomization test. For each formal variable, I constructed 100 samples, with only one contrast per language randomly selected, and ran the binomial test again with the help of an $\mathrm{R}$ script. After that I took the maximal $p$-values for each formal variable that were generated by the randomization procedure. All adjusted $p$-values were less than 0.0001 , which means that the biases in the positive direction are highly statistically significant.

\subsection{Analysis of formal types}

7 The construction with $p \hat{\imath}$ 'give' can be used only with intransitives as a valency increasing device. With transitives, it retains its benefactive-directional meaning. It is also available as a causativizer only when the Causee is in the third person (Matisoff 1976: 430). 
Although the traditional causative types (lexical, morphological and syntactic) do not provide a perfect match for cross-linguistic data, as was shown in Section 1, it would still be interesting to see whether the effects observed in Section 3.1 vary for different types of causatives. This subsection compares the formal parameters in three different situations:

a) when both $\mathrm{X}$ and $\mathrm{Y}$ are morphological;

b) when $\mathrm{X}$ is morphological and $\mathrm{Y}$ is syntactic;

c) when both $\mathrm{X}$ and $\mathrm{Y}$ are syntactic.

No lexical causatives were considered because they are not described in grammars systematically.

It goes without saying that the language-internal descriptive categories used for identification of these constructional types may not always be adequate for cross-linguistic comparisons (Haspelmath 2010), but I will use these categories as a proxy. As morphological causatives I considered affixal derivations, root changes, augmentations, reduplications and tonal changes (cf. Dixon 2000). Under the label of syntactic causatives, I conflated monoclausal verbal compounds, serial verbs, light verbs and biclausal periphrastic causatives. A finer-grained classification would be very problematic, due to the relative scarcity of these constructions in the data. Labile verb patterns and clitics were excluded as intermediate types, as well as a few pairs where the status of one of the causatives was dubious. In particular, this was the case with the Basque causative verb or suffix -(e)raz (Hualde \& Ortiz de Urbina 2003: 593).

Morphological $\mathrm{X}$ and $\mathrm{Y}$ with the (in)directness distinction are observed in 20 languages and 21 contrasting pairs. The counts for the latter are shown in Table 3.

Table 3: Formal parameters associated with (in)directness of causation: number of contrasting pairs when $\mathrm{X}$ and $\mathrm{Y}$ are morphological

\begin{tabular}{cccc}
\hline Parameter & $\mathrm{X}<\mathrm{Y}$ & $\mathrm{X}=\mathrm{Y}$ & $\mathrm{X}>\mathrm{Y}$ \\
\hline Distance & 3 & 18 & 0 \\
Autonomy & 0 & 21 & 0 \\
Productivity & 10 & 10 & 1 \\
Length & 15 & 4 & 2 \\
\hline
\end{tabular}

One can see that length is again the most strongly associated with (in)directness, but this time it is followed by productivity. The fact that all pairs of $\mathrm{X}$ and $\mathrm{Y}$ have the same level of autonomy is not surprising, since autonomy was measured on the basis of the same morphosyntactic cline in (11), which was also used for determining whether a construction is lexical, morphological or syntactic. The exceptions $(\mathrm{X}>\mathrm{Y})$ were already explained in the previous section. The only positive bias that is statistically significant, however, is displayed by length (maximal adjusted $p=0.01$ ), according to the binomial test based on resampling (see the description of the procedure in Section 3.1). Counting the languages instead of the constructional pairs yields an identical picture. 
Let us now examine the pairs with a morphological $\mathrm{X}$ and syntactic $\mathrm{Y}$. The total number of contrasting pairs is 33 in 21 languages. The counts for the contrasts are displayed in Table 4. This time, autonomy asymmetries are present in all pairs, but this is an artefact of the definitions of morphological and syntactic causatives, as mentioned above. This is why it is not shown in the table. We will see that length is again in the leading role, followed by distance. This time, productivity is the least strongly associated parameter. All positive biases are statistically significant, based on the binomial test (all maximal adjusted $p<0.001)$. Counting the languages gives the same picture as counting the contrasting pairs of constructions.

Table 4: Formal parameters associated with (in)directness of causation: number of contrasting pairs when $\mathrm{X}$ is morphological and $\mathrm{Y}$ is syntactic

\begin{tabular}{l|c|c|c}
\hline \multicolumn{1}{c|}{ Parameter } & $\mathrm{X}<\mathrm{Y}$ & $\mathrm{X}=\mathrm{Y}$ & $\mathrm{X}>\mathrm{Y}$ \\
\hline Distance & 30 & 3 & 0 \\
Productivity & 24 & 9 & 0 \\
Length & 31 & 2 & 0 \\
\hline
\end{tabular}

Finally, I have found twelve contrasts and eight languages when both $\mathrm{X}$ and $\mathrm{Y}$ are syntactic causatives. The counts for the contrasts are presented in Table 5.

Table 5: Formal parameters associated with (in)directness of causation: number of contrasting pairs when $\mathrm{X}$ and $\mathrm{Y}$ are syntactic

\begin{tabular}{l|c|c|c}
\hline \multicolumn{1}{c|}{ Parameter } & $\mathrm{X}<\mathrm{Y}$ & $\mathrm{X}=\mathrm{Y}$ & $\mathrm{X}>\mathrm{Y}$ \\
\hline Distance & 4 & 8 & 0 \\
Autonomy & 2 & 10 & 0 \\
Productivity & 2 & 10 & 0 \\
Length & 5 & 7 & 0 \\
\hline
\end{tabular}

Again, length is the most prominent parameter. It is followed by distance. Autonomy and productivity have the same counts. The biases are observed again, but they do not reach statistical significance, probably due to the small sample size. The counts of languages instead of contrasts show the same picture.

\section{Discussion}

The results of the analyses presented in Section 3 show that in general, all factors seem to be associated with (in)directness in the predicted direction at a statistically significant level. The constructions that express indirect causation are either more distant/ autonomous/productive/longer than the constructions that express direct causation $(\mathrm{X}<\mathrm{Y})$, 
or are as distant/autonomous/productive/long as those $(\mathrm{X}=\mathrm{Y})$. The exceptions $(\mathrm{X}>\mathrm{Y})$ are very scarce. This shows that all previous accounts have some grain of truth.

However, one can see that relative length is the parameter which is the most strongly associated with the distinction, both in the whole data set and in each constructional type. The results thus favour Haspelmath's (2008) explanation based on the principle of economy. Indirect causation forms are longer than direct causation forms because the former are less frequent than the latter, which results in an efficient form-meaning mapping. There is preliminary evidence that this claim is supported empirically by the relative frequencies of direct and indirect causation in spoken corpora of different languages (work in progress).

In addition, we also observed variation in the strength of the other formal parameters depending on the type of causatives compared. If one compares morphological causatives, a direct causation construction will also tend to be more productive than an indirect causation construction, but we observe no or hardly any differences with regard to autonomy and distance. However, if one compares morphological and syntactic causatives, productivity becomes the least strongly associated parameter, outperformed by length and distance (autonomy does not count here due to the methodological reasons explained in Section 3.2), although all biases are still statistically significant. A similar tendency is observed when one compares syntactic causatives, but the results do not reach statistical significance, most likely due to the small sample size.

It is time to revisit Shibatani \& Pardeshi's (2002) claim that productivity is the formal parameter that is more associated with (in)directness than the traditional formal types, i.e. lexical, morphological and syntactic causatives. Following this claim, one would expect productivity differences to appear more systematically in the data than autonomy, since the latter forms the basis for the classification. However, my data show that productivity is more relevant than autonomy only when we compare two morphological causatives, one being less productive than the other. As for the other causatives examined in this study, productivity fails to play a prominent role. This finding is not surprising because Shibatani \& Pardeshi had a bias towards morphological causatives in their study. This parameter seems to gain in importance for those causatives that are at a late stage of grammaticalization.

Distance is also particularly prominent when the direct causative is morphological and the indirect causative is syntactic. It is almost as important as length. This can be explained again by the difference in grammaticalization, since morphemes, unlike auxiliaries, tend to have a fixed position very close to their hosts. As a result, their potential for variability in distance is rather limited.

All this shows that the formal differences depend on the type of constructions and the level of grammaticalization of the causativizing elements. Yet, the pervasiveness of length asymmetries suggests that economy-related effects may be more universal than the others. I hope that future research will shed light on the historical stages in the development of causative constructions and the principles that function at the different stages of grammaticalization, so that the causal relationships between the formal and semantic parameters could be described with greater precision. Another task for the future is the investigation of variation in the marking of the core arguments (the Causee and the ob- 
ject), since in many languages, this marking reflects (in)directness, representing the role of the Causee in the caused event (cf. Comrie 1976; Kemmer \& Verhagen 1994).

\section{Acknowledgements}

This project has received funding from the European Research Council (ERC) under the European Union's Horizon 2020 research and innovation programme (grant agreement $\mathrm{n}^{\circ}$ 670985). The author is very grateful to the anonymous reviewers and the editors of this special issue for their insightful and constructive suggestions. All usual disclaimers apply.

\section{Abbreviations}

1+2 - first person plural inclusive; ACC - accusative; DAT - dative/benefactive/malefactive; CAUS causative; CONV - converb; F - feminine; FO - feminine object; IMMP - immediate past; IND - indicative; $\mathrm{M}$ - masculine; NAR - narrative; NPST - non-past; o - object; OBJ - objective case; PART - particle; PERF - perfective; PL - plural; PRO - pronoun; RECP - recent past; SG - singular; SUP - supine.

\section{Appendix}

List of languages (families). The genetic classification is provided according to the WALS.

Africa (5):

Gumuz (Gumuz), Humburi Senni (Songhay), Khoekhoe/Nama (Khoe-Kwadi), Ma'di (Central Sudanic), Noon (Niger-Congo)

Australia (3):

Diyari (Pama-Nyungan), Garrwa (Garrwan), Kayardild (Tangkic)

Eurasia (13):

Ainu (Ainu), Basque (Basque), Betta Kurumba (Dravidian), Finnish (Uralic), Great Andamenese (Great Andamenese), Hebrew (Afro-Asiatic), Hindi (Indo-European), Japanese (Japanese), Korean (Korean), Kusunda (Kusunda), Lahu (Sino-Tibetan), Nivkh (Nivkh), Yukaghir Kolyma (Yukaghir)

North America (12):

Caddo (Caddoan), Cherokee (Iroquoian), Chimariko (Hokan), Creek (Muskogean), Filomeno (Totonacan), Lakhota (Siouan), Mutsun (Penutian), Northern Paiute (Uto-Aztecan), Slave (Na-Dene), Takelma (Takelma), Teribe (Chibchan), Wappo (Wappo-Yukian)

Papua and Austronesia (4):

Indonesian (Austronesian), Motuna (East Bougainville), Skou (Skou), Yimas (Lower Sepik-Ramu)

South America (9):

Aguaruna (Jivaroan), Apinayé (Macro-Ge), Hup (Nadahup), Mocoví (Guaicuruan), Mosetén (Mosetenan), Trumai (Trumai), Urarina (Urarina), Waimiri-Atroarí (Cariban), Yagua (Peba-Yaguan) 


\section{References}

Amberber, Mengistu. 2000. Valency-changing and valency-encoding devices in Amharic. In Dixon, R. M. W. \& Aikhenvald, Alexandra Y. (eds.), Changing valency: Case studies in transitivity, 312-332. Cambridge: Cambridge University Press.

Bruno, Ana Carla. 2003. Waimiri Atroari Grammar: Some Phonological, Morphological, and Syntactic Aspects. Tucson, AZ: University of Arizona. (Doctoral dissertation.)

Bybee, Joan L., Perkins, Revere \& Pagliuca, William. 1994. The Evolution of Grammar: Tense, Aspect, and Modality in the Languages of the World. Chicago/London: The University of Chicago Press.

Comrie, Bernard. 1976. The syntax of causative constructions: Cross-language similarities and divergencies. In Masayoshi, Shibatani (ed.), Syntax and Semantic 6: The Grammar of Causative Constructions, 261-312. New York: Academic Press.

Comrie, Bernard. 1981. Language universals and linguistic typology: Syntax and morphology. Chicago: University of Chicago Press.

Dixon, R. M. W. 2000. A typology of causatives: Form, syntax and meaning. In Dixon, R. M. W. \& Aikhenvald, Alexandra Y. (eds.), Changing valency: Case studies in transitivity, 30-83. Cambridge: Cambridge University Press.

Dryer, Matthew S. \& Haspelmath, Martin (eds.). 2013. The World Atlas of Language Structures Online. Leipzig: Max Planck Institute for Evolutionary Anthropology. http://wals.info. (Accessed on 2017-01-03.)

Evans, Nicholas D. 1995. A Grammar of Kayardild: With Historical-Comparative Notes on Tangkic (Mouton Grammar Library 15). Berlin: Mouton de Gruyter.

Givón, Talmy. 1980. The binding hierarchy and the typology of complements. Studies in Language 4(3). 333-377.

Goldberg, Adele E. 1995. Constructions. A Construction Grammar Approach to Argument Structure. Chicago: The University of Chicago Press.

Haiman, John. 1983. Iconic and economic motivation. Language 59(4). 781-819.

Haiman, John. 1985. Natural syntax: Iconicity and erosion. Cambridge: Cambridge University Press.

Haspelmath, Martin. 2008. Frequency vs. iconicity in explaining grammatical asymmetries. Cognitive Linguistics 19(1). 1-33.

Haspelmath, Martin. 2010. Comparative concepts and descriptive categories in cross-linguistic studies. Language 86(3). 663-687.

Haspelmath, Martin. 2016. Universals of causative and anticausative verb formation and the spontaneity scale. Lingua Posnaniensis 58(2). 33-63.

Hualde, José Ignacio \& Ortiz de Urbina, Jon (eds.). 2003. A Grammar of Basque. Berlin: De Gruyter Mouton.

Kemmer, Susanne \& Verhagen, Arie 1994. The grammar of causatives and the conceptual structure of events. Cognitive Linguistics 5. 115-156.

Kulikov, Leonid. 2001. Causatives. In Haspelmath, Martin \& König, Ekkehard \& Oesterreicher, Wulf \& Raible, Wolfgang (eds.), Language Typology and Language Universals. An International Handbook. Vol. 2, 886-898. Berlin, New York: Walter de Gruyter.

Lehmann, Christian. 1995. Thoughts on Grammaticalization. Munich: Lincom Europa.

Levshina, Natalia. 2016. Why we need a token-based typology: A case study of analytic and lexical causatives in fifteen European languages. Folia Linguistica 50(2). 507-542.

Matisoff, James A. 1976. Lahu causative constructions: case hierarchies and the morphology/syntax cycle in a Tibeto-Burman perspective. In Shibatani, Masayoshi (ed.), Syntax and Semantic 6: The Grammar of Causative Constructions, 413-442. New York: Academic Press.

McFarland, Teresa Ann. 2009. The phonology and morphology of Filomeno Mata Totonac. Berkeley: University of California Berkeley. (Doctoral dissertation.)

Nedjalkov, Vladimir P. \& Otaina, Galina A. 2013. A Syntax of the Nivkh Language: The Amur dialect (Studies in Language Companion Series 139). Amsterdam: John Benjamins.

Nedyalkov, Vladimir P. \& Silnitsky, Georgij G. 1973. The typology of morphological and lexical causatives. In Ferenc, Kiefer (ed.), Trends in Soviet Theoretical Linguistics, 1-32. Dordrecht: Reidel.

Okrand, Marc. 1977. Mutsun grammar. Berkeley: University of California Berkeley. (Doctoral dissertation.)

Olawsky, Knut. 2006. A Grammar of Urarina (Mouton Grammar Library 37). Berlin: Mouton de Gruyter.

R Core Team. 2016. R: A language and environment for statistical computing. R Foundation for Statistical Computing, Vienna, Austria. https://www.R-project.org. (Accessed 2017-01-21) 